\title{
Usabilidad y facturación: ¿cuál es su relación en comercio electrónico?
}

\author{
Nuria Puente ${ }^{1}$
}

\begin{abstract}
Resumen. Con el objetivo de analizar la relación entre usabilidad y facturación en el ámbito del comercio electrónico español del sector gran consumo se realiza una evaluación heurística de los diez sitios web de comercio electrónico del sector gran consumo que más facturan en España (Mercadona, El Corte Inglés, Carrefour, Día, Alcampo, Eroski, Caprabo, Ulabox, Tu Despensa e HiperDirect). La definición y operacionalización de las variables de la investigación toma como referencia el Modelo de Usabilidad Web propuesto por Fernández (2009) a partir del estándar de usabilidad ISO/IEC 25000 (SQuaRE, Software, Quality Requirement Evaluation), ya que descompone las genéricas y abstractas subcaracterísticas definidas por SQuaRE en atributos cercanos al dominio web e incluye métricas web que permiten detectar problemas de usabilidad y cuantificar los atributos, lo que garantiza una mayor objetividad, criterio fundamental en las investigaciones cualitativas. El benchmarking resultante de aplicar esta técnica permite transferir el conocimiento de las mejores prácticas sobre usabilidad y su aplicación al sector analizado, lo que permite reducir la brecha existente entre investigación académica y práctica empresarial, pues ayuda a las empresas a saber cuáles son las características de cada una de las dimensiones de usabilidad que deben mejorar y, por tanto, dónde tienen que invertir sus recursos para mejorar la calidad de la experiencia de sus clientes. Además, les permite saber cuáles son las variables sobre las que deben hacer palanca para hacerlo de forma eficaz y en qué competidores pueden fijarse en función de la característica concreta que quieran mejorar.
\end{abstract}

Palabras clave: comercio electrónico; usabilidad; evaluación heurística; gran consumo.

\section{[en] Usability and billing: how is the relationship in e-commerce?}

\begin{abstract}
In order to analyze the relationship between usability and billing in the Spanish e-food sector, a heuristic evaluation of the ten billing leaders e-commerce websites in Spain (Mercadona, El Corte Inglés, Carrefour, Día, Alcampo, Eroski, Caprabo, Ulabox, Tu Despensa and HiperDirect). The definition and operationalization of the research variables is done according to the Web Usability Model proposed by Fernández (2009) based on the ISO/IEC 25000 (SQuaRE, Software, Quality Requirement Evaluation) usability standard because it decomposes the generic and abstract subcharacteristics defined by SQuaRE in attributes of the web domain and includes web metrics that allow us to detect usability problems and quantify the attributes, which guarantees a greater objectivity, fundamental criterion in the qualitative investigations. The benchmarking resulting from applying this technique allows us to know the best usability practices and apply them to the analyzed sector. This allows us to reduce the gap between academic research and business practice, because it helps companies to know what characteristics of each of the usability dimensions must improve and, therefore, where they have to invest their resources to improve the quality of the experience of its customers. In addition, it allows companies to know which variables should improve and in which competitors can be set in each case. In addition, it allows companies to know which variables should improve and in which competitors can be set in each case.
\end{abstract}

Keywords: e-commerce; usability; heuristic evaluation; e-food.

Universidad Antonio de Nebrija

npuente@nebrija.es 
Sumario. 1. Introduccción 2. Revisión de la literatura 3. Metodología 4. Resultados 5. Conclusiones y otras consideraciones finales

Cómo citar: Puente, N. (2017). Usabilidad y facturación: ¿cuál es su relación en comercio electrónico?, Cuadernos de Estudios Empresariales, 27, 43-64.

\section{Introducción}

En un contexto en el que la tipología de los formatos comerciales se ha multiplicado, la competencia se ha endurecido y son mayores las alternativas a disposición del cliente para efectuar sus compras (ahora incrementadas por las Tecnologías de la Información y la Comunicación), los detallistas se esfuerzan por conquistar al consumidor mediante la búsqueda de nuevas ideas para fidelizar a los clientes, dado que las fórmulas basadas en el marketing tradicional han disminuido su eficacia debido al propio dinamismo del sector (Zorrilla, 2002). Durante las últimas décadas, Internet se ha convertido en un nuevo canal de compra que cada vez más clientes han adoptado. Sin embargo, la adquisición online de productos de gran consumo es todavía un fenómeno de lento crecimiento en comparación con otros sectores debido a que los artículos de supermercado son los más difíciles de comercializar por esta vía (Müller-Lankenau, Wehmeyer y Klein, 2005). Resulta destacable la incorporación de una proporción significativa de los distribuidores más importantes a este nuevo negocio digital: desde El Corte Inglés y los hipermercados (Carrefour, Alcampo y Eroski) hasta los supermercados (Caprabo y Mercadona, entre otros). Sin embargo, el desarrollo de las empresas de distribución en Internet todavía no ha alcanzado la suficiente madurez en España, y sigue siendo hoy, una apuesta testimonial y de prestigio (Martínez, Saco y Fernández, 2007). A pesar de ello, en la actualidad el mercado online de gran consumo está en manos de las cadenas de distribución tradicionales, es decir, con presencia en el mundo offline. En concreto, estas enseñas acaparan el $89 \%$ del mercado, frente al $11 \%$ de los pure players, cuyas ventas representan el 1,5\% de la facturación total de los brick\&click, a pesar de que éstos no acaban de impulsar este canal de venta (Gran Consumo TV, 2013). Ante esta situación, el objetivo de esta investigación es analizar la relación entre usabilidad y facturación en el ámbito del comercio electrónico español del sector gran consumo.

\section{Revisión de la literatura}

El diseño web centrado en el usuario plantea el tipo de experiencia que se pretende que éste viva, siguiendo una máxima irrevocable: ayudarle a lograr sus objetivos. Un sitio web útil, funcional y fácil de utilizar deja libre el camino para tener una buena experiencia, eliminando las distracciones problemáticas de la interfaz (Anderson, 2011). A lo largo de la literatura son varios los estudios que identifican las variables ambientales del sitio web como un factor clave para el desarrollo de un 
establecimiento virtual de éxito por el hecho de poseer la capacidad de ejercer efectos directos sobre los estados internos del consumidor, afectando a sus actitudes y condicionando su comportamiento (Lorenzo, 2006. Puente, 2016).

Tomando como referencia los estándares oficiales de usabilidad definidos por la Organización Internacional de Estandarización, como la ISO 9241 - Ergonomics of human System Interaction (ISO, 2011b), la ISO 13407 - Human centred design processes for interactive systems (ISO, 2010), la ISO 9126 - Software engineering - Product quality (ISO, 2011a), la ISO 14598 - Information technology - Software product evaluation (ISO, 2012), y la ISO/IEC 25000 - SQuaRE, Software, Quality Requirement Evaluation (ISO, 2014), se puede definir usabilidad como la "medida con la que un producto se puede usar por usuarios determinados para conseguir objetivos específicos con efectividad, eficiencia y satisfacción en un contexto de uso concreto" y/o como "la capacidad que tiene un producto de software para ser entendido, aprendido, operable, atractivo para el usuario y conforme a los estándares/ guías cuando es utilizado bajo unas condiciones específicas". En definitiva, la usabilidad es una medida de la calidad de la experiencia de los usuarios en un sitio web y como tal, son varias las investigaciones que giran en torno a ella. Un buen ejemplo es la de Flavián, Guinalíu y Gurrea (2004), quienes concluyeron que la usabilidad se encuentra positiva y directamente relacionada con el nivel de confianza y satisfacción del cliente. Sin embargo, son pocos los estudios que analizan la usabilidad en el ámbito del comercio electrónico de gran consumo y éste es uno de los motivos por lo que esta investigación se considera pionera.

\section{Metodología}

Con el objetivo de analizar la relación entre usabilidad y facturación en el ámbito del comercio electrónico español del sector gran consumo se apuesta por utilizar la técnica de la evaluación heurística, la cual se lleva a cabo con los diez e-commerce del sector gran consumo de base alimentaria con mayor facturación (Mercadona, El Corte Inglés, Carrefour, Día, Alcampo, Eroski, Caprabo, Ulabox, Tu Despensa e HiperDirect), que son los que, de acuerdo con otras investigaciones (Flavián y Gurrea, 2003. Martínez, Saco y Fernández, 2007), dan pie un análisis más completo. Para llevar a cabo la evaluación heurística se definen y operacionalizan las variables de la investigación (tabla 1) tomando como referencia el Modelo de Usabilidad Web propuesto por Fernández (2009) (concretamente, la parte que contempla la usabilidad en uso), cuyas principales aportaciones son la descomposición de las genéricas y abstractas subcaracterísticas definidas por la ISO/IEC 25000 (SQuaRE) en atributos cercanos al dominio web, intentando que las definiciones de los atributos se solapasen entre sí lo mínimo posible; y la inclusión de métricas web genéricas que permiten detectar problemas de usabilidad y cuantificar los atributos. 
Tabla 1. Definición y operacionalización de variables

\begin{tabular}{|c|c|c|}
\hline \multicolumn{3}{|c|}{ VARIABLE: Usabilidad (grado de cumplimiento del estándar ISO/IEC 25000) } \\
\hline \multicolumn{3}{|c|}{ ATRIBUTO: Facilidad de entendimiento } \\
\hline CARACTERÍSTICAS & SUBCARACTERÍSTICAS & TIPO DE VARIABLE \\
\hline \multirow{4}{*}{ Legibilidad visual } & \multirow{3}{*}{$\begin{array}{l}\text { Adecuación de las caracterís- } \\
\text { ticas del texto a cada contexto }\end{array}$} & Cuantitativa discreta (tamaño de la fuente) \\
\hline & & $\begin{array}{l}\text { Cualitativa nominal dicotómica (uso mayoritario de } \\
\text { tipografía sans serif: sí/no; o de serif con tamaño } \\
\text { grande: sí/no) }\end{array}$ \\
\hline & & $\begin{array}{l}\text { Cualitativa nominal dicotómica (predominio del co- } \\
\text { lor gris en el texto: sí/no) }\end{array}$ \\
\hline & Diseño responsive & $\begin{array}{l}\text { Cualitativa nominal dicotómica (existencia de scroll } \\
\text { horizontal en pantallas pequeñas: sí/no) }\end{array}$ \\
\hline \multirow[t]{2}{*}{ Facilidad de lectura } & $\begin{array}{l}\text { Agrupación cohesiva de la in- } \\
\text { formación }\end{array}$ & $\begin{array}{l}\text { Cualitativa nominal dicotómica (existencia de un } \\
\text { sistema de navegación jerárquico con información } \\
\text { cohesionada en núcleos temáticos: sí/no) }\end{array}$ \\
\hline & $\begin{array}{l}\text { Densidad de información } \\
\text { adecuada }\end{array}$ & $\begin{array}{l}\text { Cualitativa nominal dicotómica (existencia de un } \\
\text { sistema de filtros: sí/no) }\end{array}$ \\
\hline Familiaridad & $\begin{array}{l}\text { Cumplimiento de los están- } \\
\text { dares }\end{array}$ & Cualitativa nominal dicotómica (sí/no) \\
\hline \multirow[t]{2}{*}{ Ahorro de esfuerzo } & $\begin{array}{l}\text { Flexibilidad y eficiencia en } \\
\text { el uso }\end{array}$ & $\begin{array}{l}\text { Cualitativa nominal dicotómica (completitud de des- } \\
\text { cripciones y claridad de los elementos de la interfaz: } \\
\text { sí/no) }\end{array}$ \\
\hline & Atajos & $\begin{array}{l}\text { Cualitativa nominal dicotómica (existencia de ele- } \\
\text { mentos para reducir el esfuerzo cognitivo: sí/no) }\end{array}$ \\
\hline \multirow{2}{*}{ Orientación al usuario } & \multirow{2}{*}{$\begin{array}{l}\text { Retroalimentación o visibi- } \\
\text { lidad del estado del sistema } \\
\text { para reducir los tiempos de } \\
\text { latencia }\end{array}$} & $\begin{array}{l}\text { Cualitativa nominal dicotómica (existencia de feed- } \\
\text { back del sistema hacia el usuario: sí/no) }\end{array}$ \\
\hline & & $\begin{array}{l}\text { Cualitativa ordinal (calidad de los mensajes de avi- } \\
\text { so: buena/mala) }\end{array}$ \\
\hline \multirow{4}{*}{ Navegabilidad } & \multirow{4}{*}{ Facilidad para navegar } & $\begin{array}{l}\text { Cualitativa nominal dicotómica (disponibilidad de } \\
\text { búsqueda interna: sí/no) }\end{array}$ \\
\hline & & $\begin{array}{l}\text { Cualitativa nominal dicotómica (fácil identificación } \\
\text { de enlaces: sí/no) }\end{array}$ \\
\hline & & $\begin{array}{l}\text { Cualitativa nominal dicotómica (fácil interconectivi- } \\
\text { dad del contenido: sí/no) }\end{array}$ \\
\hline & & $\begin{array}{l}\text { Cualitativa nominal dicotómica (fácil alcanzabilidad } \\
\text { del contenido a través de la navegación: sí/no) }\end{array}$ \\
\hline \multicolumn{3}{|c|}{ ATRIBUTO: Facilidad de aprendizaje } \\
\hline CARACTERÍSTICAS & SUBCARACTERÍSTICAS & TIPO DE VARIABLE \\
\hline \multirow{2}{*}{ Predictibilidad } & \multirow{2}{*}{$\begin{array}{l}\text { Facilidad para predecir el re- } \\
\text { sultado de las acciones que } \\
\text { va a realizar basándose en los } \\
\text { elementos de la interfaz }\end{array}$} & $\begin{array}{l}\text { Cualitativa nominal dicotómica (etiquetado de enla- } \\
\text { ces significativo: sí/no) }\end{array}$ \\
\hline & & $\begin{array}{l}\text { Cualitativa nominal dicotómica (estandarización de } \\
\text { los controles: sí/no) }\end{array}$ \\
\hline
\end{tabular}




\begin{tabular}{|c|c|c|}
\hline \multirow[t]{2}{*}{ Potencialidad } & \multirow[t]{2}{*}{$\begin{array}{l}\text { Determinación de acciones } \\
\text { posibles y prometedoras }\end{array}$} & $\begin{array}{l}\text { Cualitativa nominal dicotómica (fácil identificación } \\
\text { por parte del usuario de las acciones que le permiti- } \\
\text { rán avanzar hacia la consecución de su objetivo: sí } \\
\text { no) }\end{array}$ \\
\hline & & $\begin{array}{l}\text { Cualitativa nominal dicotómica (existencia de múlti- } \\
\text { ples salidas en el sistema de navegación: síno) }\end{array}$ \\
\hline \multirow{2}{*}{$\begin{array}{l}\text { Retroalimentación in- } \\
\text { formativa }\end{array}$} & \multirow{2}{*}{$\begin{array}{l}\text { Información que se propor- } \\
\text { ciona al usuario sobre el re- } \\
\text { sultado de las acciones que se } \\
\text { han llevado a cabo con ante- } \\
\text { rioridad }\end{array}$} & $\begin{array}{l}\text { Cualitativa nominal dicotómica (existencia de ele- } \\
\text { mentos que indican al usuario su ubicación: sí/no) }\end{array}$ \\
\hline & & $\begin{array}{l}\text { Cualitativa nominal dicotómica (existencia de ele- } \\
\text { mentos que indican el progreso de una transacción: } \\
\text { sí/no) }\end{array}$ \\
\hline \multicolumn{3}{|c|}{ ATRIBUTO: Facilidad de uso } \\
\hline CARACTERÍSTICAS & SUBCARACTERÍSTICAS & TIPO DE VARIABLE \\
\hline \multirow{2}{*}{ Gestión de los datos } & \multirow{2}{*}{$\begin{array}{l}\text { Robustez / prevención de } \\
\text { errores y gestión sencilla de } \\
\text { los mismos }\end{array}$} & $\begin{array}{l}\text { Cualitativa nominal dicotómica (proporción de me- } \\
\text { canismos de validación de datos de entrada: sí/no) }\end{array}$ \\
\hline & & $\begin{array}{l}\text { Cualitativa nominal dicotómica (proporción de me- } \\
\text { canismos de protección de datos: sí/no) }\end{array}$ \\
\hline \multirow{4}{*}{ Controlabilidad } & \multirow{4}{*}{$\begin{array}{l}\text { Libertad, control y tolerancia } \\
\text { para que el usuario pueda de- } \\
\text { sarrollar un comportamiento } \\
\text { autónomo dentro de la web }\end{array}$} & $\begin{array}{l}\text { Cualitativa nominal dicotómica (capacidad de modi- } \\
\text { ficar acciones: sí/no) }\end{array}$ \\
\hline & & $\begin{array}{l}\text { Cualitativa nominal dicotómica (capacidad de can- } \\
\text { celar acciones: sí/no) }\end{array}$ \\
\hline & & $\begin{array}{l}\text { Cualitativa nominal dicotómica (capacidad de des- } \\
\text { hacer acciones: síno) }\end{array}$ \\
\hline & & $\begin{array}{l}\text { Cualitativa nominal dicotómica (capacidad de reha- } \\
\text { cer acciones: sí/no) }\end{array}$ \\
\hline \multirow{2}{*}{ Consistencia } & \multirow{2}{*}{$\begin{array}{l}\text { Comportamiento y orden } \\
\text { constante de los enlaces y } \\
\text { controles }\end{array}$} & $\begin{array}{l}\text { Cualitativa nominal dicotómica (consistencia de en- } \\
\text { laces: sí/no) }\end{array}$ \\
\hline & & $\begin{array}{l}\text { Cualitativa nominal dicotómica (consistencia de } \\
\text { controles: síno) }\end{array}$ \\
\hline \multicolumn{3}{|c|}{ ATRIBUTO: Facilidad de ayuda } \\
\hline CARACTERÍSTICAS & SUBCARACTERÍSTICAS & TIPO DE VARIABLE \\
\hline $\begin{array}{l}\text { Completitud de la ayu- } \\
\text { da online }\end{array}$ & $\begin{array}{l}\text { Mecanismos de ayuda y aten- } \\
\text { ción al cliente }\end{array}$ & $\begin{array}{l}\text { Cualitativa nominal dicotómica (completitud de la } \\
\text { ayuda online: sí/no) }\end{array}$ \\
\hline $\begin{array}{l}\text { Documentación mul- } \\
\text { ti-usuario }\end{array}$ & $\begin{array}{l}\text { Personalización del contenido } \\
\text { para el target }\end{array}$ & $\begin{array}{l}\text { Cuantitativa discreta (número de idiomas disponi- } \\
\text { bles). }\end{array}$ \\
\hline \multirow{3}{*}{$\begin{array}{l}\text { Completitud del mapa } \\
\text { del sitio }\end{array}$} & \multirow{3}{*}{$\begin{array}{l}\text { Visión global de la estructura } \\
\text { de la web }\end{array}$} & $\begin{array}{l}\text { Cualitativa nominal dicotómica (existencia de mapa } \\
\text { del sitio: síno) }\end{array}$ \\
\hline & & $\begin{array}{l}\text { Cualitativa nominal dicotómica (posición siempre } \\
\text { visible del mapa del sitio: sí/no) }\end{array}$ \\
\hline & & $\begin{array}{l}\text { Cualitativa nominal dicotómica (completitud del } \\
\text { mapa del sitio: sí/no) }\end{array}$ \\
\hline $\begin{array}{l}\text { Calidad de los mensa- } \\
\text { jes de asesoramiento }\end{array}$ & $\begin{array}{l}\text { Indicaciones sencillas y di- } \\
\text { rectas que sirvan de ayuda al } \\
\text { usuario. }\end{array}$ & $\begin{array}{l}\text { Cualitativa ordinal (calidad de los mensajes de ase- } \\
\text { soramiento: buena/mala) }\end{array}$ \\
\hline
\end{tabular}




\begin{tabular}{|l|l|l|}
\hline \multicolumn{2}{|l|}{ ATRIBUTO: Grado de atracción } \\
\hline CARACTERÍSTICAS & SUBCARACTERÍSTICAS & TIPO DE VARIABLE \\
\hline Consistencia & $\begin{array}{l}\text { Uniformidad de colores, } \\
\text { fuentes y secciones }\end{array}$ & $\begin{array}{l}\text { Cualitativa nominal dicotómica (interfaz consisten- } \\
\text { te: sí/no) }\end{array}$ \\
\hline \multirow{2}{*}{ Personalización } & $\begin{array}{l}\text { Posibilidad de que el usuario } \\
\text { modifique las características } \\
\text { estéticas de la interfaz }\end{array}$ & $\begin{array}{l}\text { Cualitativa nominal dicotómica (posibilidad de per- } \\
\text { sonalización estética: sí/no) }\end{array}$ \\
\hline Interactividad & $\begin{array}{l}\text { Posibilidad de que el usuario } \\
\text { modifique la forma y el fondo } \\
\text { de la web }\end{array}$ & $\begin{array}{l}\text { Cualitativa nominal dicotómica (posibilidad de mo- } \\
\text { dificar la forma de visualización: sí/no) }\end{array}$ \\
\cline { 2 - 3 } & $\begin{array}{l}\text { Cualitativa nominal dicotómica (posibilidad de mo- } \\
\text { dificar el contenido: sí/no) }\end{array}$ \\
\hline
\end{tabular}

Fuente: Adaptación de Fernández (2009)

Dada la gran amplitud del surtido de los e-commerce seleccionados, hay que aclarar que, a pesar de que se ha navegado en profundidad por todos los sitios web, para realizar una evaluación abarcable se seleccionaron sólo las páginas más relevantes con las que se encuentra el consumidor en el proceso de la compra (homepage, página de categoría y/o subcategoría, ficha de producto, página del carrito, de registro y/o checkout). Todas las revisiones se realizaron entre los meses de marzo y junio de 2016, como nuevo cliente, por lo que no había cuentas existentes ni historial de navegación previo. Asimismo, es necesario mencionar las especificaciones técnicas más relevantes del medio ambiente de la evaluación, ya que pueden condicionar los resultados: dispositivo HP Pavilion dv7 Notebook PC, sistema operativo Windows 7, navegador Google Chrome (versión 41.0.2272.118 m), conexión a Internet 30Mb WIFI, tamaño del monitor: 17,3", color del monitor: 64 bits y resolución del monitor: $1.600 \times 900$.

\section{Resultados}

Desde un punto de vista general, el cumplimiento medio de los e-commerce analizados con el Modelo de Usabilidad Web propuesto por Fernández (2009) es del 80,9\%, un valor muy positivo para el comercio electrónico español del sector gran consumo. Este valor alcanza el $100 \%$ en lo que a "facilidad de uso" se refiere, el $86,6 \%$ en lo relacionado con la "facilidad de aprendizaje", el $81,5 \%$ en lo tocante a la "facilidad de entendimiento", el 76,6\% respecto a la "facilidad de ayuda" y el 61\% en el "grado de atracción". Además, es preciso tener en cuenta tres ideas. Primero, que el rango entre el peor y el mejor nunca supera los 5 puntos (alcanzando este valor sólo en el caso de "facilidad de entendimiento" y "de aprendizaje"), lo que indica que las diferencias entre los e-commerce analizados no son excesivamente grandes. Segundo, que el valor mínimo no está nunca por debajo de 5 , lo que indica que, incluso en el caso en que los e-commerce deben mejorar, superan unos requisitos mínimos. Y tercero, que el valor máximo es 10 es en "facilidad de entendimiento", "facilidad de aprendizaje" y "facilidad de uso", lo que indica que todos los e-commerce pueden hacerlo bien si se lo proponen. Por último, es preciso reseñar que, desde un punto de vista individual, Ulabox lidera claramente el ranking, junto con HiperDirect y Día; 
seguidos por Tu Despensa, Eroski y El Corte Inglés. Después se sitúan Carrefour, Caprabo, Alcampo y, en última posición, Mercadona.

Para comprender mejor estas puntuaciones, es preciso analizar con detalle los resultados de cada atributo, característica y subcaracterística de la usabilidad.

\section{a) Facilidad de entendimiento}

La puntuación media de los e-commerce analizados en este apartado es de 8,2 puntos sobre $10(\mathrm{~S}=1,5)$, lo que lo sitúa en tercera posición respecto al resto de dimensiones de la usabilidad y encima de la media general $(8,09)$. Como se aprecia en el gráfico 1, destaca la amplitud del rango de puntuaciones, ya que, mientras que Día y Ulabox dominan características como la legibilidad visual, la facilidad de lectura, la familiaridad, el ahorro de esfuerzo, la orientación al usuario y la navegabilidad, Mercadona y Alcampo aún tienen mucho que mejorar.

Gráfico 1. Resultados de la evaluación heurística: facilidad de entendimiento (I)

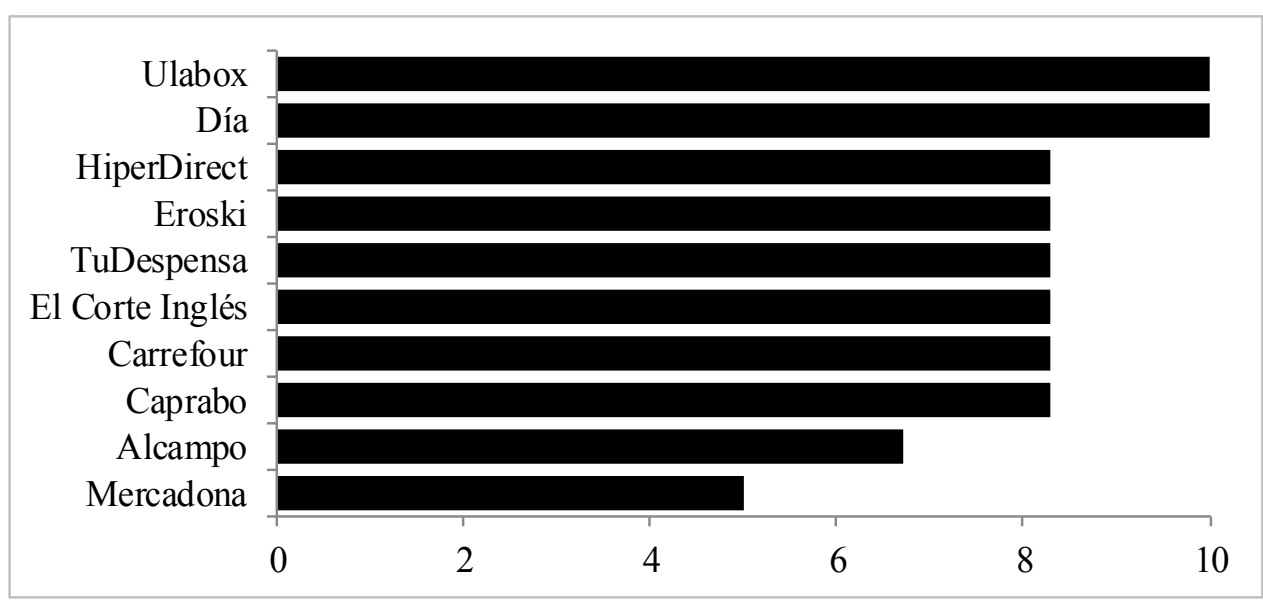

Fuente: elaboración propia

Si se analizan cada una de las características del atributo "facilidad de entendimiento" se aprecia que, como puede verse en el gráfico 2, la característica mejor valorada de todas es el "ahorro de esfuerzo", ya que todos los e-commerce apuestan por reducir el esfuerzo cognitivo del usuario mediante la posibilidad de completar las acciones en pocos segundos (ej. funcionalidades avanzadas del buscador interno), la transmisión de información de la forma más clara y concisa posible y el desarrollo de funcionalidades de la interfaz que permiten que el usuario aproveche el tiempo y el esfuerzo invertidos la primera vez para identificar los productos deseados (ej. listas de la compra, histórico de pedidos). Le siguen la "navegabilidad" y la "facilidad de lectura", donde la puntuación anterior se repite de nuevo en todos, excepto en Mercadona, cuya arquitectura de la información no supera los requisitos mínimos, debido a la reducida visibilidad de su buscador interno y a su apuesta por un sistema de navegación restrictivo. 
Gráfico 2. Resultados de la evaluación heurística: facilidad de entendimiento (II)

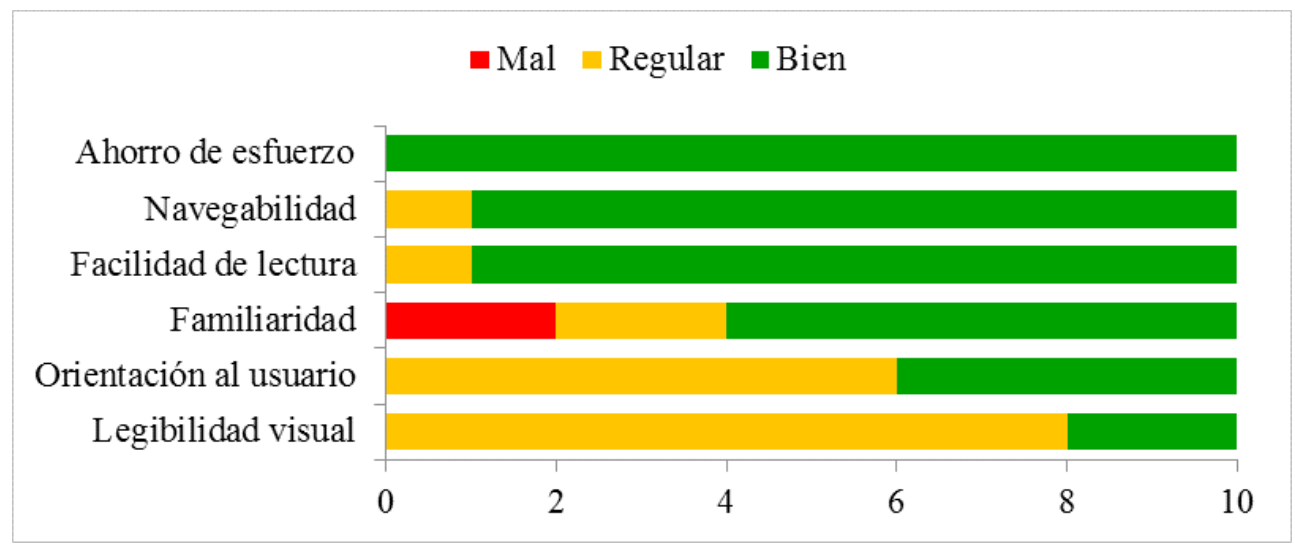

Fuente: elaboración propia

La siguiente característica con mayor número de valoraciones positivas es la "familiaridad", aunque en este caso dos de los diez e-commerce han obtenido una puntuación regular (Eroski y Tu Despensa) y dos una mala (Mercadona y Alcampo). No obstante, el caso más impactante es el de Mercadona, que ni tiene fichas de producto, ni utiliza imágenes del producto, ni tiene unos botones predecibles para buscar productos y añadirlos al carrito. Por último, cierran la lista la "orientación al usuario", dominada sólo por Eroski, Día, Ulabox y Tu Despensa, que proporcionan al usuario un feedback claro para facilitar su compra, y la "legibilidad visual", característica en la que destacan Día y Ulabox, debido, principalmente, a su diseño responsive.

Para comprender mejor las puntuaciones anteriores, se hace una valoración detallada de cada atributo y sus características:

- Legibilidad visual:

- Características del texto: de acuerdo con las propuestas de Nielsen y Loranger (2007), en la mayoría de los e-commerce el tamaño de la letra (mínimo 12 puntos), la tipografía utilizada (serif en casi totas las ocasiones) y el color predominante en la interfaz (gris) hacen que la legibilidad visual sea adecuada para todo tipo de públicos. La principal desviación de estas normas se produce con el tamaño de la letra, siendo Mercadona y Alcampo los máximos exponentes.

- Diseño responsive: en este punto se valora que el contenido se adapte al tamaño de la pantalla, evitando que el usuario tenga que hacer scroll horizontal para leerlo. De todos los supermercados online, sólo Día y Ulabox están optimizados, aunque Tu Despensa tiene un enlace en el pie de web a la versión móvil.

- Facilidad de lectura:

- Cohesión: en la mayoría de los casos, la información está bien cohesionada en torno a un mismo núcleo temático en todos los niveles, lo que facilita que el usuario pueda profundizar en el sistema de navegación jerárquico. 
- Densidad: en este caso se valora si la cantidad de información que se ofrece al usuario le produce una sensación de sobrecarga. Para ello, teniendo en cuenta que la navegación es libre en casi todos los e-commerce, se presta especial atención al sistema de filtros, que permite al usuario eliminar bloques completos de información de las páginas de categoría (El Corte Inglés, Día, Alcampo, Ulabox, Tu Despensa, HiperDirect); y al diseño en capas de la ficha de producto (Carrefour, Ulabox), pues, independientemente de la densidad del e-commerce, ambos ayudan al usuario a tomar las riendas de la navegación al permitirle elegir qué quiere ver y qué no. Merece la pena destacar también en este bloque el caso de Mercadona, cuya navegación es restrictiva, de manera que obliga al usuario a elegir el nivel más bajo de subcategoría antes de mostrarle los productos. Con esta forma de operar consigue ofrecerle un menor número de referencias, lo que agilizaría su lectura, si el e-commerce tuviera alguna imagen, ya que el usuario no tendría que leer tanto para discriminar entre productos.

- Familiaridad: la mayoría de los e-commerce cumplen con la heurística de la estandarización (representan los conceptos con los mismos formatos, utilizan metáforas cotidianas y cumplen con los estándares para mejorar la facilidad de entendimiento del sitio web); aunque otros como Tu Despensa, Eroski, Alcampo y Mercadona, no siempre. De estos dos últimos, el caso más notorio es el de Mercadona, que no tiene páginas de producto propiamente dichas, no utiliza imágenes ni fotografías, y no tiene, como se explica a continuación, unos botones predecibles para buscar productos y añadirlos al carrito. Alcampo, por su parte, no tiene botones para añadir los productos al carrito ${ }^{2}$. Y en el caso de Tu Despensa y Eroski, la novedad se debe a la apertura de algunas de sus páginas (las de subcategoría, producto y/o checkout) en un pop-up interior, comportamiento muy diferente al del resto de competidores y empresas ajenas al sector.

- Ahorro de esfuerzo:

- Listas: todos los e-commerce menos Tu Despensa permiten al usuario crear tantas listas como desee, pudiendo añadir después todos los productos al carrito con sólo un clic.

- Histórico de pedidos: en todos los supermercados analizados es posible acceder a los pedidos realizados anteriormente, pudiendo repetirlos total o parcialmente de forma rápida y sencilla. En Carrefour, por ejemplo, dan un paso más y no sólo muestran "Mis productos habituales comprados online", sino también "Mis productos habituales comprados en el híper", por lo que potencian la omnicanalidad facilitando así la compra recurrente. Otro de los e-commerce que destaca en este aspecto es Tu Despensa, ya que cuenta con un call to action evidente: antes de comprar recomienda al usuario que elabore una lista con "lo que quiere comprar" o "lo que suele comprar". En el primer caso, sólo hay que escribir los productos y hacer clic en el botón "Comenzar a comprar". Automáticamente, el primer producto de la lista se añade en el buscador interno y la interfaz muestra los resultados de la búsqueda. En la segun-

Hay que aumentar el número de unidades de los productos que, por defecto, es cero. 
da opción, conocida como "la compra super-rápida", se muestran todos los productos comprados en pedidos anteriores ordenados por categorías, lo que evita al usuario buscar lo que necesita entre todo el surtido disponible.

- Otras funcionalidades: dentro de este bloque destacan las funcionalidades avanzadas del buscador interno. En Carrefour y en El Corte Inglés, las denominadas "búsqueda express" y "compra express", respectivamente, que permiten al usuario escribir una lista de productos y buscarlos todos a la vez. Y en Ulabox y en Eroski, la existencia de un botón de compra en el propio buscador (además de en las páginas de categoría, funcionalidad común en todos los supermercados online analizados).

- Orientación al usuario: en todos los e-commerce el sistema proporciona feedback al usuario cuando añade un producto al carrito, lo incluye en una lista o realiza otras acciones importantes. Sin embargo, en algunos es más visible que en otros. En Ulabox, Eroski y Día se reemplaza el botón "añadir al carrito" por el número de unidades compradas y los botones necesarios para aumentar o disminuir esta cifra, lo que facilita que el usuario sea capaz de saber, con un solo vistazo a la página de categoría o de producto, qué referencias ha añadido al carrito. Por el contrario, en Mercadona, El Corte Inglés, Carrefour, Alcampo, Caprabo, HiperDirect y Tu Despensa apenas se aprecian cambios en estas páginas cuando el usuario se encuentra ante un producto que ya está en su cesta pues, a no ser que el número de unidades sea mayor que uno (en cuyo caso varía el número), el diseño es idéntico al de los demás productos, lo que obliga al usuario a prestar mucha más atención. No obstante, en este último se confirma la acción mediante el deslizamiento de la imagen del producto hacia la zona del carrito. Y en Tu Despensa, mediante una breve animación.

- Navegabilidad: la arquitectura de la información de Ulabox es excelente en todos sus aspectos: soporte a la búsqueda interna y características del sistema de navegación (clickabilidad, interconectividad y alcanzabilidad). Le siguen Día, Tu Despensa, HiperDirect, El Corte Inglés, Eroski y Carrefour, aunque en este último hay que realizar una lectura más atenta. En el lado opuesto, la navegabilidad de Mercadona es mejorable, sobre todo en lo relacionado con el buscador interno, cuya visibilidad es reducida.

\section{b) Facilidad de aprendizaje}

La puntuación media de los e-commerce en este apartado es de 8,6 puntos ( $\mathrm{S}=2)$, lo que lo sitúa en segunda posición y, al igual que en el caso anterior, por encima de la media general $(8,09)$. En este caso, tal y como se aprecia en el gráfico 3, la puntuación de los pure players es excelente, ya que controlando características como la "predictibilidad", la "potencialidad" y la "retroalimentación informativa" y apostando por heurísticas como la consistencia, los estándares y la visibilidad del estado del sistema para la reducción de los tiempos de latencia, consiguen que el usuario pueda utilizar la web de manera rápida e intuitiva incluso la primera vez, lo que reduce las barreras de entrada. Respecto a los brick\&click, cuya puntuación media es de 8,1, hay que destacar el trabajo de El Corte Inglés, Eroski y Día, ya que su excelente puntuación contrasta con la de Mercadona y Alcampo. 
Gráfico 4. Resultados de la evaluación heurística: facilidad de aprendizaje (I)

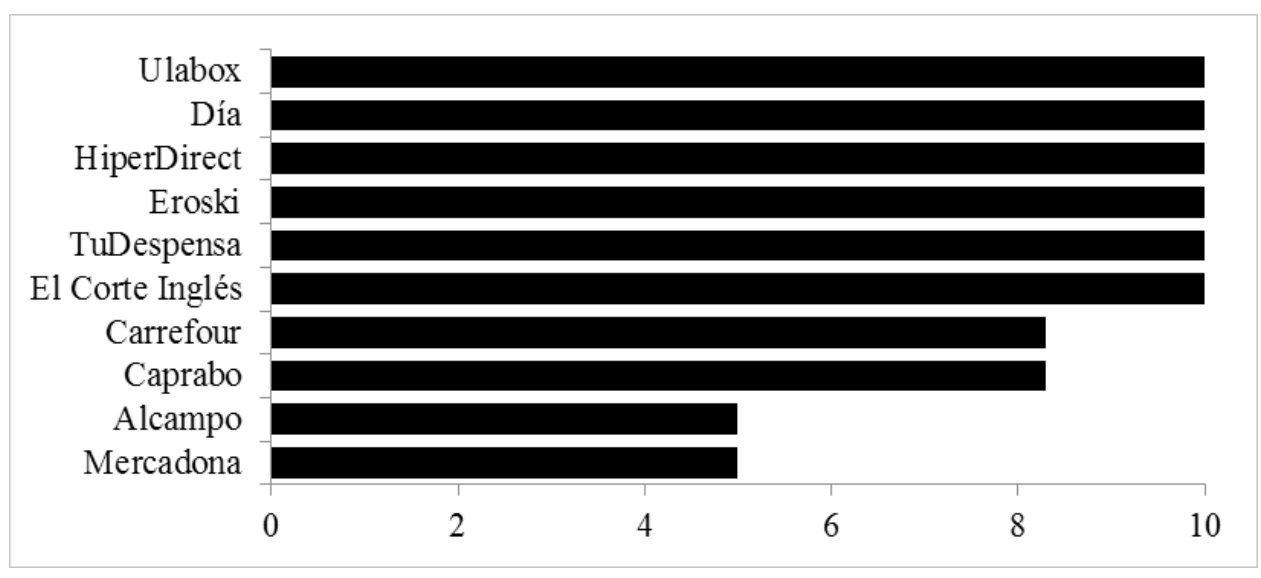

Fuente: elaboración propia

Si se analizan cada una de las características del atributo "facilidad de aprendizaje" se aprecia, como puede verse en el gráfico 4, que la característica mejor valorada es la "retroalimentación informativa", ya que todos los supermercados han conseguido una buena puntuación, debido al uso de elementos visuales, breadcrumbs e indicadores de progreso para informar al usuario de su ubicación actual. Le sigue la "potencialidad", con siete e-commerce bien posicionados (todos a excepción de Mercadona, Caprabo y Alcampo, que apuestan por una navegación mucho más restrictiva que el resto). En último lugar se encuentra la "predictibilidad" que, aunque también ha obtenido la máxima puntuación en siete de los diez supermercados, está por debajo en el ranking debido a la mala puntuación de Mercadona y Alcampo, quienes no cumplen con los estándares (Mercadona por el diseño de su botón para añadir un producto al carrito y Alcampo por la ausencia de dicho botón).

Gráfico 4. Resultados de la evaluación heurística: facilidad de aprendizaje (II)

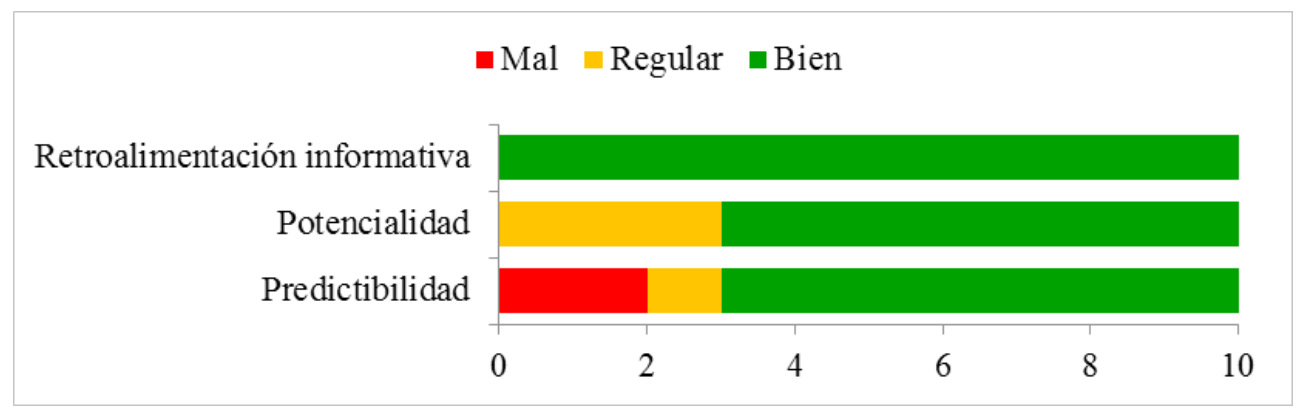

Fuente: elaboración propia 
Para comprender mejor las puntuaciones anteriores, se hace una valoración detallada de cada atributo y sus características:

- Predictibilidad:

- Etiquetado de los enlaces: los e-commerce analizados apuestan por un sistema de organización formado por esquemas ambiguos que aportan una mayor riqueza a la navegación, pero requieren cierto aprendizaje debido a que las taxonomías no son exactas. No obstante, el hecho de que dicha categorización se corresponda con la del supermercado físico y sea igual o muy parecida en todas las empresas evita posibles desorientaciones del usuario, aumentando así la efectividad y la eficiencia. La excepción viene de la mano de Carrefour, donde estas categorías son ligeramente diferentes, al mezclarse las tiendas especializadas de los fabricantes (ej. "Tienda Nestlé") con las categorías de productos (ej. "aceites y vinagre"), las marcas (ej. Cruzcampo), las secciones de productos sin gluten, sin lactosa, ecológicos, gourmet, dietéticos y las de surtido internacional ("alemán", "francés"), entre otras ("especial barbacoa", "los más vendidos", "nuestros recomendados"), lo que obliga a los usuarios a leer todas las etiquetas que, por cierto, no aparecen en orden alfabético.

- Controles: todos, excepto Mercadona y Alcampo, apuestan por la estandarización. En el primero, lo que más llama la atención son los botones con los que el usuario puede añadir un producto al carrito, ya que están representados únicamente por el isotipo de la marca. Y en el segundo, la ausencia de este botón.

- Potencialidad: el sistema de organización está formado en todos los e-commerce, excepto en Mercadona, en Alcampo y en Caprabo, por una estructura jerárquica que fomenta la flexibilidad de la navegación ${ }^{3}$, por lo que el usuario puede realizar varias acciones en una misma página. No obstante, la existencia de unos call to action claros facilita que éste sepa en todo momento cuáles son las acciones más relevantes, es decir, las que le harán avanzar secuencialmente hacia la conversión. Dentro de esta dinámica, merece la pena destacar el hecho de que en todos los sitios web siempre hay, independientemente de dónde se encuentre el usuario, unas partes de la interfaz fijas, lo que proporciona al usuario múltiples salidas. Generalmente, son las zonas superior e inferior, que es donde se encuentran el logotipo, el buscador, el menú, el carrito y los enlaces a la información más relevante, aunque en el caso de Mercadona también permanecen inmutables los laterales, que es donde se encuentran repartidos los elementos anteriores. La única excepción a esto se encuentra en Ulabox y en Eroski, donde en las páginas correspondientes al proceso de checkout se eliminan por completo las distracciones, dejando visible únicamente el logotipo, lo que da al usuario sólo dos opciones: finalizar el proceso de compra o hacer clic en el logotipo para volver a la página de inicio.

\footnotetext{
En estos tres casos, la navegación se define como restrictiva porque durante el proceso de búsqueda, evaluación y selección de los productos no permite al usuario ver cualquier punto del catálogo, sino que le obliga a elegir el nivel más bajo de subcategorías. No se trata, por tanto, de una navegación restrictiva pura y, teniendo en cuenta que estos e-commerce no poseen sistemas de filtrado, se considera una buena opción, ya que así el número de productos mostrados es menor.
} 
- Retroalimentación informativa:

- Ubicación actual: todos los e-commerce informan al usuario de en qué punto de la estructura de navegación se encuentra mediante la utilización de elementos visuales (iconos, sangrías y colores) en el menú (Mercadona) y/o breadcrumbs (Carrefour, Día y Ulabox). Además, cuando hay filtros seleccionados que condicionan el contenido visible, éstos aparecen destacados. En Carrefour, cada vez que el usuario le pide un cambio de página al sistema, éste le muestra un pop-up informativo con el texto "gracias por esperar mientras carga la página..." para que sepa que ha recibido su orden.

- $\quad$ Proceso de checkout: es habitual que las páginas que cierran el proceso de compra cuenten con un indicador de progreso en la parte superior, aunque Mercadona y El Corte Inglés aglutinan todos los pasos en una sola página.

\section{c) Facilidad de uso}

Tanto los pure players como los brick\&click cuidan las características de "gestión de los datos", "controlabilidad" y "consistencia", y trabajan adecuadamente las heurísticas de libertad, control y tolerancia, prevención de errores y gestión sencilla de los mismos, por lo que su puntuación en este atributo es la máxima posible (10) haciendo que sea el primero de la lista.

- Gestión de los datos: en esta sección se valoran tanto los mecanismos de validación de los datos de entrada (en la mayoría de las ocasiones, visibles sólo cuando el usuario comete algún error al completar el formulario), como los mecanismos de protección de datos. En este último caso, el análisis se centra en dos elementos fundamentales: la contraseña (que en todos los e-commerce tiene un formato de seguridad que la hace invisible por defecto) y la tarjeta de crédito (que en algunos e-commerce como Ulabox puede guardarse, aunque se explica claramente que no lo hacen ellos sino el banco). Conviene mencionar también que en todos los supermercados analizados se pide al usuario antes de comenzar el proceso de compra que introduzca su código postal para comprobar si la empresa sirve ahí sus pedidos y no pierda el tiempo haciendo un pedido que no le va a llegar.

- Controlabilidad:

- Datos personales: en todos los e-commerce analizados se otorga al cliente la libertad de ver y modificar en cualquier momento la información de la cuenta (datos de contacto y de acceso, criterios de sustitución de productos, preferencias de visualización y/o listas), de manera que su actualización o corrección no provoque efectos perjudiciales en el correcto funcionamiento de la web. En el caso de Tu Despensa, el usuario puede, además, reservar ofertas durante 22 días sin ningún tipo de compromiso.

- Acciones: en relación con el resto de operaciones, el usuario también tiene total libertad para modificar sus acciones, deshacerlas, rehacerlas, cancelarlas e interrumpirlas, pudiendo incluso modificar (Mercadona 
y Ulabox) o cancelar (Mercadona) un pedido ya pagado (si no se ha empezado a preparar).

- Consistencia: todos los e-commerce analizados cumplen con esta heurística, puesto que sus elementos son coherentes con la ley de la similitud de la psicología Gestalt. Los enlaces se mantienen siempre en la misma posición de la interfaz, apuntan al mismo destino si tienen el mismo nombre y aparecen en el mismo orden si pertenecen al mismo grupo. Los controles siempre se comportan de la misma forma, respetan su posición respecto a otros para no confundir al usuario y sólo aparecen si las funciones asociadas a ellos se pueden realizar. Asimismo, las etiquetas se corresponden con las acciones que representan.

\section{d) Facilidad de ayuda}

La puntuación media de este atributo es de 7,7 ( $\mathrm{S}=1,1)$, lo que lo sitúa en cuarta posición y debajo de la media general $(8,09)$. En este caso, aunque los pure players superan a los brick\&click, la diferencia entre ambos grupos no es muy acusada, por lo que los dos tienen un considerable margen de mejora a la hora de ofrecer respuestas rápidas a los problemas comunes de los usuarios. Como se aprecia en el gráfico 5, el valor mínimo viene de la mano de Carrefour, Caprabo y Día; mientras que el máximo está representado por Mercadona, Eroski, Alcampo e HiperDirect.

Gráfico 5. Resultados de la evaluación heurística: facilidad de ayuda (I)

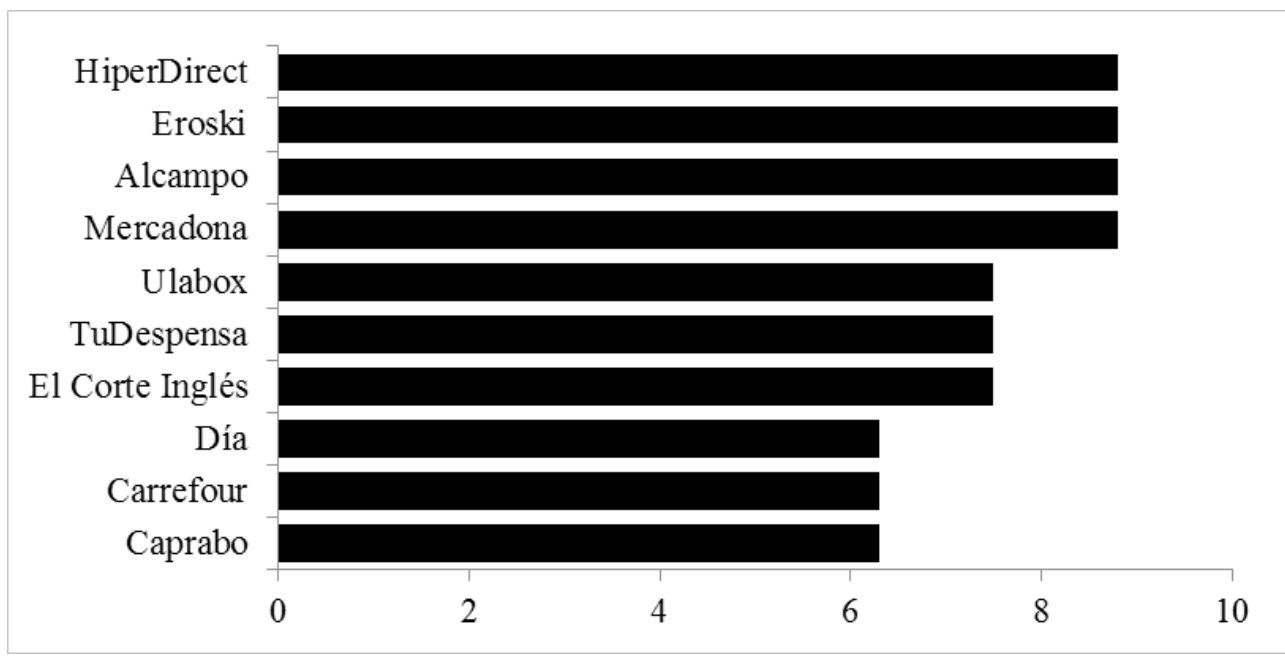

Fuente: elaboración propia

Si se analizan cada una de las características del atributo "facilidad de ayuda" se aprecia, como puede verse en el gráfico 6, que las mejor valoradas son la "completitud de la ayuda online" y la "documentación multi-usuario", ya que todos los supermercados han obtenido una buena puntuación en ellas gracias a la existencia de una sección de ayuda con información detallada sobre la empresa, el funcionamiento del 
sitio web, las respuestas a una serie de preguntas frecuentes, y la existencia de múltiples formas de contacto. La siguiente característica en el ranking es la "calidad de los mensajes de asesoramiento", con una puntuación positiva en la mitad de los supermercados (Mercadona, El Corte Inglés, Eroski, Alcampo y Tu Despensa) gracias al uso de textos alternativos, iconos explicativos y otros elementos de diseño web que facilitan la experiencia de compra. En último lugar se encuentra la "completitud del mapa del sitio", cuya puntuación dista mucho de las anteriores al contar sólo con una valoración positiva (HiperDirect) y cuatro regulares (Mercadona, Eroski, Alcampo y Ulabox), ya que el resto no tiene mapa del sitio.

Gráfico 6. Resultados de la evaluación heurística: facilidad de ayuda (II)

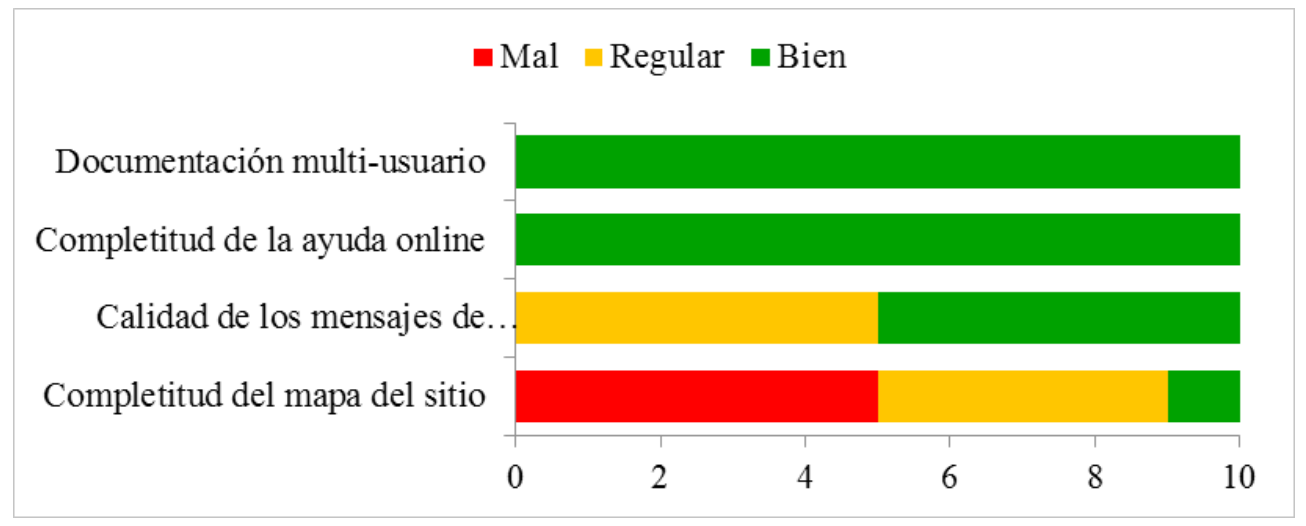

Fuente: elaboración propia

Para comprender mejor las puntuaciones anteriores, se hace una valoración detallada de cada atributo y sus características:

- Completitud de la ayuda online:

- Sección "Ayuda": ya sea con este nombre o con el de "guía de compra" u otros similares, todos los supermercados informan al usuario de cómo funciona su sitio web y de qué tiene que hacer para completar determinadas tareas, información muy básica, comprensible por todo tipo de públicos, que resulta de gran interés en los primeros contactos.

- "Preguntas frecuentes": aunque en la mayoría de las ocasiones la información proporcionada en otras secciones es suficiente, Carrefour, El Corte Inglés, Ulabox y Tu Despensa cuentan con una sección FAQ (Frequently Asked Questions), que aúna y responde las dudas más comunes de los usuarios.

- Otras páginas informativas: en todos los e-commerce hay páginas adicionales con información legal y comercial relacionada con el proceso de compra. Además, Carrefour añade numerosos enlaces en el pie de web a páginas que amplían la información sobre el grupo.

- Atención al cliente: en todos los e-commerce analizados se muestran múltiples formas de contacto con el departamento de atención al cliente (email, teléfono, formulario de contacto y/o redes sociales, además de un asistente virtual en Eroski). 
- Documentación multi-usuario: desde el punto de vista de los idiomas, la mitad de los supermercados sólo utiliza uno (castellano), por lo que el público objetivo queda limitado al territorio español, aunque esto no supone un problema porque es precisamente ésta la zona que cubren sus envíos. En Caprabo es posible elegir entre castellano y catalán; en Carrefour, entre castellano, catalán e inglés; y en Mercadona, entre esos tres, euskera, gallego, valenciano y alemán. Sin embargo, en este último caso, la elección debe hacerse antes de iniciar sesión, lo que resulta poco intuitivo para el usuario. En El Corte Inglés se puede elegir entre castellano, inglés y alemán; en Alcampo, entre castellano, catalán, euskera, gallego, francés, inglés y alemán; y, en Eroski, entre todos los anteriores, excepto francés.

- Completitud del mapa del sitio:

- Existencia: todos los e-commerce tienen uno, excepto El Corte Inglés, Carrefour, Caprabo, Día y Tu Despensa.

- $\quad$ Posición: lo más frecuente es que se sitúe en el pie de web, aunque el de Mercadona está en la parte superior derecha de la interfaz.

- Contenido: aunque en el de Mercadona y en el de Eroski sólo hay enlaces relacionados con el proceso de compra online o con la empresa, y en el de Alcampo y Ulabox sólo se agrupan jerárquicamente los productos del catálogo en categorías y subcategorías, lo ideal es que el mapa del sitio incluya ambos tipos de información, como es el caso del de HiperDirect, que, por cierto, a diferencia de los demás, muestra los enlaces del mismo nivel jerárquico ordenados alfabéticamente, lo que facilita su consulta y, por tanto, que el usuario alcance sus objetivos.

- Calidad de los mensajes de asesoramiento:

- Textos alternativos: todos los supermercados utilizan textos alternativos (meta-etiquetas alt del código fuente), visibles con forma de tooltip cuando el usuario pasa el cursor por encima, que especifican la funcionalidad de algunos botones (ej. "aumentar la cantidad de productos", "hacer clic para ampliar la imagen", "abre nueva ventana"), indican el significado de algunos iconos (ej. "refrigerado", "ecológico", "sin gluten", "sin lactosa", "sin huevo", "vegano", "producto de peso variable") y/o añaden a las imágenes el nombre del producto asociado.

- Consejos antes de empezar: nada más iniciar sesión, Mercadona muestra siempre al usuario una guía de compra, donde le explica qué pasos debe llevar a cabo y cuál es el significado de los iconos. Alcampo y Eroski, por su parte, le informan de cómo funcionan sus e-commerce. En Tu Despensa se divide el proceso en dos pasos numerados: "Escribe tu lista de la compra" y "Comenzar a comprar". Además, tanto Tu Despensa como El Corte Inglés tienen uno o más vídeos donde le enseñan cómo utilizar la web.

\section{e) Grado de atracción}

La puntuación media de este atributo es $6,9(\mathrm{~S}=0,7)$, lo que lo sitúa en última posición y, al igual que en el caso anterior, debajo de la media general $(8,09)$. Como se aprecia en el gráfico 7, el valor mínimo pertenece a Mercadona, Caprabo y Ca- 
rrefour; y el máximo, a Ulabox e HiperDirect, por lo que de nuevo los pure players lideran la clasificación.

Gráfico 7. Resultados de la evaluación heurística: grado de atracción (I)

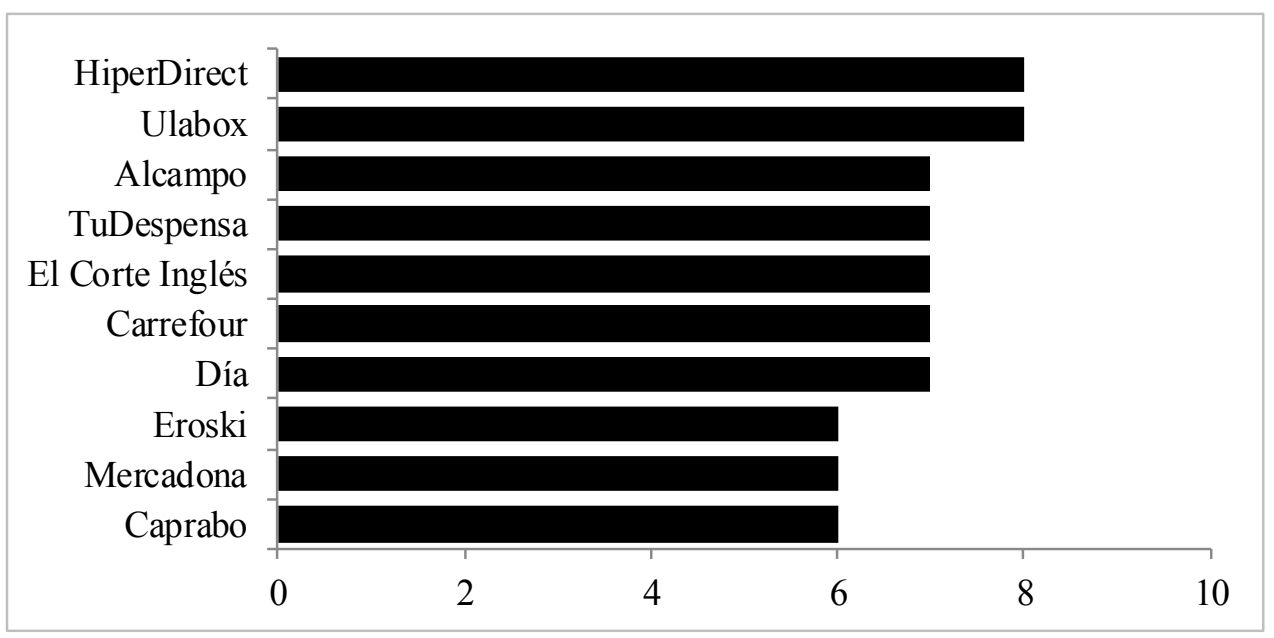

Fuente: elaboración propia

Si se analizan cada una de las características del atributo "grado de atracción" se aprecia, como puede verse en el gráfico 8, que la mejor valorada es la "consistencia", ya que todos los supermercados mantienen uniformes a lo largo de toda la interfaz tanto el color de fondo, como las fuentes, como la posición de las secciones. $\mathrm{La}$ siguiente de la lista es la "interactividad", que cuenta con una posición positiva en dos de los supermercados (Ulabox e HiperDirect) y con una negativa en tres de ellos (Mercadona, Caprabo y Eroski) tras la valoración de la posibilidad de modificar la forma y el fondo. Por último, la "personalización" es la que cierra la clasificación con una puntuación negativa en todos los supermercados, ya que ninguno permite que el usuario modifique a su gusto las características estéticas de la interfaz.

Gráfico 8. Resultados de la evaluación heurística: grado de atracción (II)

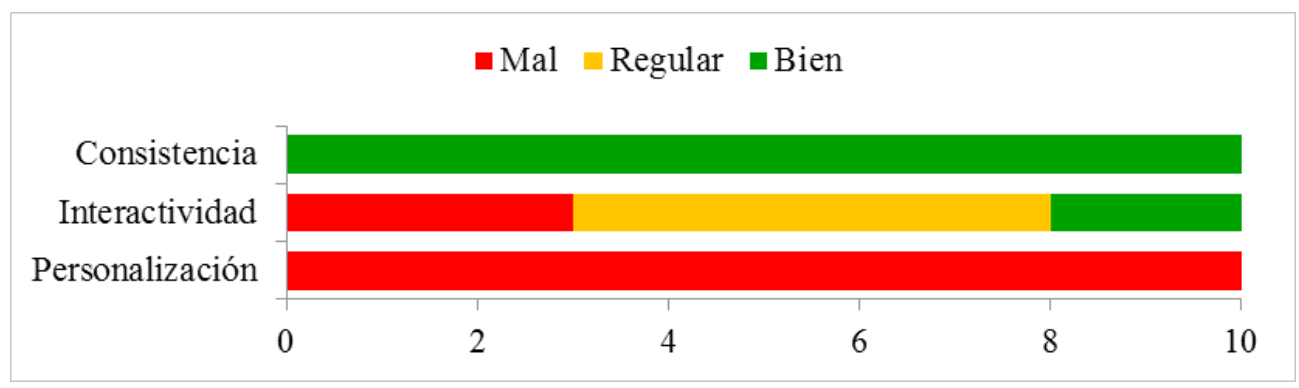

Fuente: elaboración propia 
Para comprender mejor las puntuaciones anteriores, se hace una valoración detallada de cada atributo y sus características:

- Consistencia: tanto el color de fondo, como las fuentes (color, estilo y tipo), como la posición de las secciones se mantienen uniformes a lo largo de toda la interfaz en todos los e-commerce analizados.

- Personalización: el usuario no puede modificar a su gusto las características estéticas de la interfaz (color, estilos temáticos) en ningún supermercado.

- Interactividad:

- Posibilidad de modificar la forma: dentro de este bloque se encuentran las opciones de la interfaz que permiten al usuario elegir la forma de visualización de los productos, es decir, en "listado" o en "cuadrícula" (E1 Corte Inglés, Carrefour y Ulabox) y el orden de los mismos (disponible en todos los e-commerce, excepto en Mercadona y Caprabo), así como el número de productos por página (HiperDirect). También se integra en este grupo la posibilidad de modificar el tamaño de la página mediante el zoom, funcionalidad sólo disponible en HiperDirect (visible siempre en el límite inferior del below the line).

- Posibilidad de modificar el fondo: en este grupo se incluyen los sistemas de filtrado que permiten al usuario eliminar bloques completos de contenido. Los e-commerce destacados son Alcampo, Día, Ulabox, $\mathrm{Tu}$ Despensa e HiperDirect, aunque no todos son igual de importantes. Ulabox tiene el sistema de filtros más completo y Tu Despensa ofrece a sus clientes la posibilidad de realizar una "compra super-rápida", que consiste en buscar lo que necesitan entre los productos que ya han comprado antes, en vez de entre todo el catálogo.

\section{Conclusiones y otras consideraciones finales}

El benchmarking resultante de la evaluación heurística permite transferir el conocimiento de las mejores prácticas sobre usabilidad y su aplicación al sector del comercio electrónico de gran consumo. Por tanto, y dado que en dirección de empresas se suele indicar continuamente la necesidad de eliminar o reducir la brecha existente entre investigación académica y práctica empresarial este apartado trata de enfatizar la forma en que las conclusiones de esta investigación pueden influir y mejorar la gestión de empresas.

Retomando el objetivo de la investigación (analizar la relación entre usabilidad y facturación), hay que decir que en la actualidad, en lo que a facturación se refiere, los líderes de la compra física lo son también de la compra online, ya que el e-commerce de gran consumo está en manos de las cadenas de distribución tradicionales (brick\&click) y no de los pure players, a pesar de que éstas no acaban de impulsar este canal de venta. Los resultados de la evaluación heurística corroboran que los pure players, nativos del canal digital, se caracterizan por una visión de negocio clientecéntrica y un gran dominio de las nuevas tecnologías, lo que se traduce en sitios web más usables y mejor optimizados, que, pese a tener una mayor capacidad de negociación y diversidad del surtido para satisfacer la demanda de la cesta media, sólo realizan una 
apuesta testimonial y de prestigio por el e-commerce. En esta línea, de acuerdo con las fuentes de información secundarias analizadas, no sorprende que Ulabox lidere el ranking ni que Mercadona lo cierre, pero sí que Día comparta pódium con los pure players, revelándose así como el mejor supermercado brick\&click.

Teniendo en cuenta lo anterior, donde la relación entre usabilidad y facturación parece inexistente, se considera necesario realizar una reflexión más profunda y mencionar algunas de las diferencias existentes entre ambos agentes, ya que ambos grupos no se encuentran en igualdad de condiciones, lo que ha podido condicionar el resultado. En primer lugar, los distribuidores tradicionales tienen más años de vida que los pure players, por lo que han tenido más tiempo para crecer y fidelizar a sus clientes, consiguiendo así que sus costes de captación sean menores (cognitive lock-in) (Johnson, Bellman y Lohse, 2003). En segundo lugar, hay que tener en cuenta que en las decisiones de compra de productos de gran consumo, la costumbre es decisiva, ya que se realizan compras repetidas y rutinarias en las que el hábito ejerce un peso mayor que la racionalidad, lo que aumenta las barreras de salida a la hora de buscar nuevos establecimientos de compra. Además, no hay que olvidar que la implicación con el producto (muy baja en el sector gran consumo) es una de las variables que moderan la relación entre el ambiente web y el estado emocional del comprador (Lorenzo, 2006; Puente, 2016).

Desde un punto de vista general, el grado de cumplimiento de los supermercados online analizados con el estándar ISO/IEC 25000 SQuaRE es del 81\%, lo que permite clasificar, tanto los supermercados como los atributos en función de si han superado o no este valor medio. Ahora las empresas saben cuáles son las características de cada una de las dimensiones de usabilidad que deben mejorar y, por tanto, dónde tienen que invertir sus recursos para mejorar su usabilidad y, por ende, la calidad de la experiencia de sus clientes. Además, saben cuáles son las variables sobre las que deben hacer palanca para hacer todo esto de forma eficaz y en qué competidores pueden fijarse en función de la característica concreta que quieran mejorar (ver ilustración 1).

Ilustración 1. Resultados de la evaluación heurística: ranking de supermercados online

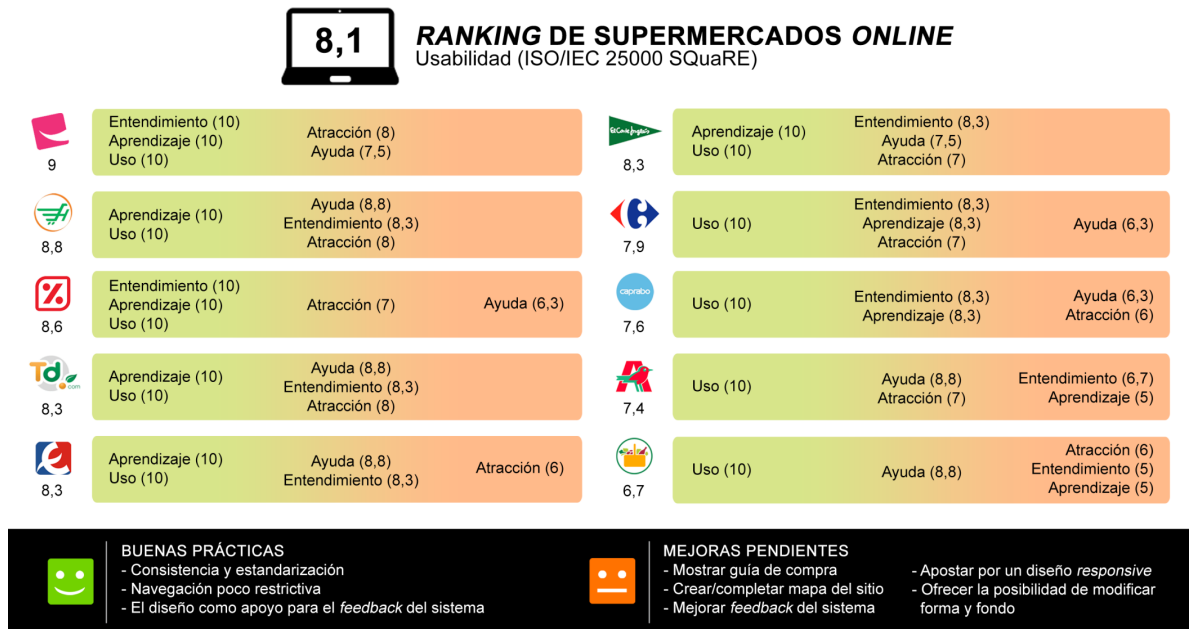

Fuente: elaboración propia 
Para concluir, partiendo de las conclusiones obtenidas en esta investigación, se incluyen a continuación algunas sugerencias de mejora que los supermercados online deberían incluir en su plan de acción:

- Facilidad de aprendizaje: para mejorar esta dimensión las empresas deben centrarse en optimizar la identificación e interpretación de los patrones de diseño.

- Potencialidad: las empresas (sobre todo, Caprabo, Alcampo y Mercadona) tienen que apostar por una navegación menos restrictiva.

- $\quad$ Predictibilidad: es necesario que las empresas analizadas (en especial Carrefour, Alcampo y Mercadona) apuesten por la estandarización de los controles, siendo urgente mejorar primero los botones para añadir productos al carrito.

- Facilidad de entendimiento: para mejorar esta dimensión las empresas deben centrarse en ayudar al usuario a procesar gran cantidad de información.

- Familiaridad: deben apostar por la estandarización. Mercadona, por ejemplo, tendría que crear fichas de producto y Eroski, por su parte, tendría que hacerlo en una página propia y no en un popup o ventana emergente. Alcampo, por su parte, debería crear un botón estándar para añadir productos al carrito.

- Orientación al usuario: las empresas (HiperDirect, Tu Despensa, El Corte Inglés, Carrefour, Caprabo, Alcampo, Mercadona) deben aportar feedback al usuario de forma clara y una buena forma de hacerlo es a través de pequeñas modificaciones en el diseño (por ejemplo, cuando éste realiza acciones importantes como añadir un producto al carrito).

- $\quad$ Legibilidad visual: es fundamental que apuesten por un diseño responsive (HiperDirect, Eroski, El Corte Inglés, Caprabo, Alcampo y Mercadona) y que en algunos casos (Alcampo y Mercadona) aumenten el tamaño de letra utilizado.

- Facilidad de ayuda: las variables en las que deben centrar sus esfuerzos son la navegabilidad, la información y el diseño.

- Calidad de los mensajes de asesoramiento: sería positivo que las empresas (Ulabox, HiperDirect, Día, Carrefour, Caprabo) crearan una guía de compra o dieran al usuario algunos consejos antes de empezar a comprar. En el caso de Ulabox, por ejemplo, sería conveniente que le informaran antes de que intente añadir un producto al carrito de que no reparten productos frescos en todos los lugares. Podrían incluso darle la oportunidad de escribir su código postal al inicio de la navegación y adaptar la web en tiempo real para mostrarle sólo los productos que puede comprar. Y en el caso de Tu Despensa, que sí dispone de vídeos donde se enseña al usuario cómo utilizar la web, sería bueno que se incluyera, además, algunos textos que permitan hacer una lectura rápida del proceso.

- $\quad$ Completitud del mapa del sitio: deben crear (El Corte Inglés, Día, Carrefour, Caprabo) o completar (Ulabox, Alcampo y Mercadona) sus mapas del sitio. En este último caso, Alcampo podría incluir en él todas las páginas que componen el sitio web y no sólo las relacionadas con productos y categorías. Mercadona, por su parte, podría incluir los 
productos y las categorías; Eroski, el listado de productos y/o subcategorías en que se dividen sus grandes categorías; y Ulabox, enlaces a información adicional al surtido, como por ejemplo la relativa al envío, el pago y la empresa.

- Grado de atracción: para mejorar esta dimensión de la usabilidad deben hacer palanca en las variables información y diseño.

- Interactividad: para mejorar esta característica, las empresas analizadas tendrían que permitir que el usuario modifique la forma (Día y Alcampo), el fondo (El Corte Inglés y Carrefour) o ambas (Eroski, Caprabo y Mercadona). En el primer caso, sería conveniente incluir en el e-commerce elementos que permitan seleccionar cómo quieren visualizarse los productos; y en el segundo, que haya un buen sistema de filtros que permita eliminar el contenido que no interese.

- Personalización: esta característica hace alusión a la posibilidad de que el usuario modifique las características estéticas de la interfaz, lo cual no es posible en ninguno de los supermercados analizados, por lo que no se considera prioritario.

\section{Referencias bibliográficas}

Anderson, S.P. (2011), Diseño que seduce. Cómo crear webs y aplicaciones atractivas al usuario. Anaya Multimedia: Madrid.

Fernández, A.; Abrahão, S. E Insfran, E. (2009). WUEP: un proceso de evaluación de usabilidad web integrado en el desarrollo de software dirigido por modelos, Tesina. Máster en Ingeniería del Software, Universidad Politécnica de Valencia.

Flavián, C. y Gurrea, R. (2003). "El empleo de Internet como nuevo canal de distribución: un análisis de sus principales ventajas e inconvenientes". Distribución y Consumo, 72, p. 64-78.

Flavián, C.; Guinalíu, M. y Gurrea, R. (2004). “Análisis empírico de la influencia ejercida por la usabilidad percibida, la satisfacción y la confianza del consumidor sobre la lealtad a un sitio web". XVI Encuentro de Profesores Universitarios de Marketing, Alicante.

Gran Consumo TV (2013). "Mercadona tiene un tercio de cuota de mercado en súper online por ventas", Gran Consumo TV, 25/04/2013. Disponible en: http://www.granconsumo.tv/ distribucion/distribucion-base-alimentaria-y-general/mercadona-tiene-un-tercio-de-cuota-de-mercado-e (accedido el 13 de junio, 2017)

ISO, International Organization For Standardization (2010). ISO 13407. Human centred design processes for interactive systems.

ISO, International Organization For Standardization (2011a). ISO 9126. Software engineering - Product quality.

ISO, International Organization For Standardization (2011b). ISO 9241. Ergonomics of human System Interaction.

ISO, International Organization For Standardization (2012). ISO 14598. Information technology - Software product evaluation.

ISO, International Organization For Standardization (2014). ISO/IEC 25000 - SQuaRE, Software, Quality Requirement Evaluation.

Johnson, E.; Bellman, S. y Lohse, G. (2003). "Cognitive lock-in and the power law of practice”. Journal of Marketing, 67 (2), p. 62-75. 
Lorenzo, C. (2006). El comportamiento del consumidor ante el diseño del punto de venta virtual: efectos e interacciones. Tesis doctoral. Universidad de Castilla-La Mancha.

Martínez, M.; Saco, M. y Fernández, R. (2007). “Análisis de los supermercados virtuales que operan en España". XX Congreso Anual de AEDEM. Palma de Mallorca.

Müller-Lankenau, C., Wehmeyer, K.y Klein, S (2005). "Multi-Channel Strategies: Capturing and Exploring Diversity in the European Retail Grocery Industry". International Journal of Electronic Commerce, 10 (2), p. 85-122.

Nielsen, J. y Loranger, H. (2007) Usabilidad. Prioridad en el diseño web. Anaya Multimedia: Madrid.

Puente, N. (2016). El e-commerce merchandising en el sector gran consumo de base alimentaria. Análisis del éxito de sus estrategias y técnicas. Tesis Doctoral. Universidad Antonio de Nebrija.

Zorrilla, P. (2002). "Nuevas tendencias en merchandising. Generar experiencias para conquistar emociones y fidelizar clientes". Distribución y Consumo, 65, p. 13-20. 